\title{
Attitudes Toward Physical Education and Physical Activities: A Comparison Study of Chinese and American High School Students
}

\author{
Yixuan Wang \\ Cambridge School of Weston, Weston, Massachusetts, USA \\ yxbwang666@163.com
}

\begin{abstract}
The Chinese structure of physical education as a high school curriculum differs greatly from that of the United States. The purpose of this study is to measure the difference in attitude toward physical education among Chinese and American high school students and to identify possible causes. Furthermore, this study aims to propose methods to improve high school physical education in order to boost student participation in physical activities. In this study, attitude is measured with the Physical Education Activity Attitude Scale (PEAAS) originally developed by Valdez in 1997 [16]. The research group is composed of 403 high school students. Data is collected via online survey platform Wenjuanxing in China and Google Forms in the U.S. and analyzed with SPSS. The result shows that there is a significant difference between the attitudes of Chinese and American high school students towards physical education, with the Chinese students scoring more favorably (Mean $=81.8$ ) than American students (Mean $=77.6)$.
\end{abstract}

Keywords: Physical Education, attitude, curriculum, high school, education.

\section{Introduction}

\subsection{Defining Attitude.}

Attitude is defined by research as a particular belief towards a subject [1]. The development of attitudes, positive or negative, is determined by a person's beliefs about a subject [1]. Attitude typically is reflected in the behaviors one displays towards the said subject and involvement in daily activities as it is largely responsible for the controlling of behaviors, thus behavior can serve as a predictor of attitude [2].

Beliefs and attitudes may be salient but can still change overtime [1,3]. The display of attitude can be verbal, such as in the forms of belief statements, or nonverbal, such as facial expressions [1].

Many factors play into the formation of an attitude. Positive experience can serve to reinforce a positive attitude or neutralize a negative attitude, and vise-versa for negative experience [1, 4]. Attitude plays a role in almost all school subjects across the curriculum [5], which makes the research of attitude critical to the development of curriculums in schooling and to the mental and physical health of school-age children and teenagers.

The importance of understanding the general attitude towards physical education lies in its long-term influence on the participation of physical activity. An important mission of physical education is to promote a lifelong habit of an active lifestyle for students [5]. It is shown that students with more positive attitudes toward physical education and such activities participate more vigorously in physical activities outside of school [6]. Physical education does not only benefit the physical development of students, but also reduces the risk of depression, anxiety, stress, and increase self-esteem and confidence [7,8]. These benefits of physical education on individual development make it one of the most effective means of raising students to be healthy and balanced physically and mentally [8] which can in turn serve the individuals and the society as a whole.

However, it is a challenge to measure attitude. While attitude is very subjective and therefore hard to quantify and measure, many instruments to measure the attitudes of individuals have been developed, mostly in the form of questionnaires. Some of the most widely used ones are the Physical Education Activity Attitude Scale (PEAAS) originally developed by Valdez [4], the Sports/Activities Preference Questionnaire developed by the Principal Investigator [9], and the SAtPE instrument Measure [5]. Interviews are also used in the investigation of attitude [4]. 


\subsection{Comparing Chinese and American Physical Education.}

This study is designed to compare the attitudes toward physical education among Chinese and American high school students, therefore it is necessary to examine the two systems for practicing physical education. The difference between the Chinese and American practice of physical education is considerable. On the one hand, physical education encompasses the development of both the body and the mind for most American high schools, while the Chinese system focuses primarily on physical achievements. There is a significantly larger variety of sports to choose from and athletics elective options available to students in American schools than those in China. On the other hand, China has a stronger emphasis on physical education as students are required to take a period of structured physical education class every school day and are given scores based on their performance in various tasks such as sprinting and gymnastics. The emphasis and the pressure to achieve in physical education classes are even more evident for high school students, since these scores are counted as part of their final score for college entrance. In many cases, physical education is not offered as a structured class in American high schools, but rather takes up the form of pass/fail or credit-based periods, which makes the curriculum less stressful, but at the same time less valued by the students.

\subsection{Contributing Factors to Attitude.}

Students' attitudes towards physical education is influenced by a great many factors. One of the most commonly acknowledged factors is age. Studies have shown age to has a negative correlation with attitude $[1,5,10]$.

The impact of gender on attitude towards physical education is still debatable. Some studies show that gender itself does not cause a significant difference between attitudes [5]. Other studies have shown boys to have a more positive attitude than girls $[11,12]$ and speculates that the difference or lack of difference may be attributed to the preferences of activities offered [4, 13].

The structure and the content of the curriculum also play a role in the formation of students' attitudes towards physical education, where variety and fun are related to a more favorable attitude $[1,2,4,14]$. Racially and ethnically marginalized students tend to have a more negative attitude towards physical education [1]. It is also found that individual athletic competency has a positive correlation with attitude towards physical education, especially shown in the negative effects on attitude for students lacking enough skills $[1,11,13,15]$.

\subsection{Objectives of Research.}

Cross-cultural comparison of attitudes towards physical education are especially lacking, and this study can fill in that vacuum. The numerous differences in the educational systems of the two countries and their impact on high school students' needs to be examined in order to find a way to enhance the physical education standards internationally. Furthermore, high school students are not popular subjects of attitude studies as many scholars tend to focus on the elementary level. However, adolescence is a critical period in one's development, and a better understanding of their attitudes towards education is essential. The objectives of this research are to:

(a) identify important contributing factors to the difference in attitudes between Chinese high school students and American high school students and the effects of age, gender, GPA, and selfperceived athletic ability on attitude towards physical education;

(b) Propose possible alternatives for high school physical education.

\section{Methods}

\subsection{Participants and Setting.}

A total of 401 high school students aged between 14 to18 (170 males, 231 females) participated in this study. There were 255 Chinese participants and 146 U.S. participants. Participants were asked to record their age at the time of the survey (December 2018 - January 2019) rounded down to the 
nearest whole number. The mean age of all participants was $16.101( \pm 1.259 \mathrm{SD})$, of Chinese participants was $16.102( \pm 1.274 \mathrm{SD})$, of U.S. participants was $16.10( \pm 1.236 \mathrm{SD})$.

GPA and self-perceived athletic ability were also collected as categorical data. Participants were required to select their GPA range (lower than 2.0, $2.0 \sim 2.5$ (not including 2.5), $2.5 \sim 3.0$ (not including 3.0), $3.0 \sim 3.5$ (not including 3.5), $3.5 \sim 4.0$ ), and self-perceived athletic ability (very low, low, moderate, high, outstanding).

\subsection{Instrumentation.}

Students' attitudes towards physical education is measured with the Physical Education Activity Attitude Scale (PEAAS), originally developed by Valdez in 1997 and proved to be reliable and valid. Participants were asked to rate 20 statements concerning attitude towards physical education and activity (10 positive statements, 10 negative statements) from 1 (strongly disagree) to 5 (strongly agree). The survey was published online via survey platform Wenjuanxing in China and Google Forms in the U.S.

\subsection{Data Analysis.}

Results collected via the above survey platforms were imported into Microsoft Excel where invalid responses (i.e. not high school age, repetitive responses) were eliminated. Negative statements were reverse-coded in order to generate valid sum of attitude scores. The date was then analyzed based on nationality, gender, age, GPA, and self-perceived athletic ability with SPSS.

\section{Results}

An independent-samples t-test was used to compare attitude scores. The result shows that there was a significant difference between the scores for Chinese participants $(\mathrm{M}=81.795, \mathrm{SD}=10.106)$ and U.S. participants $(\mathrm{M}=77.459, \mathrm{SD}=8.677) ; \mathrm{t}=4.354, \mathrm{p}<0.001$. The results suggest that Chinese high school students have a higher physical education attitude score than U.S. high school students, that it, Chinese high school students have a more desirable attitude.

Gender is also found to be an affecting factor through an independent-samples t-test. The result shows a significant difference between the scores for males $(\mathrm{M}=82.653, \mathrm{SD}=9.756)$ and females $(\mathrm{M}=78.466, \mathrm{SD}=9.517) ; \mathrm{t}=4.320, \mathrm{p}<0.001$. The results suggest that male high school students have a more desirable attitude towards physical education than their female counterparts.

A Pearson product-moment correlation coefficient was computed to evaluate the relationship between GPA and attitude score. For China and U.S. combined, there was a significantly negative correlation between the two variables, $\mathrm{r}=-0.138, \mathrm{n}=401, \mathrm{p}=0.006$. Overall, there was a weak, negative correlation between GPA and attitude score which suggests that a lower GPA is correlated with a higher attitude score. However, separate analysis of data collected from Chinese and American students suggests that the Pearson correlation is insignificant for each individual group.

Another Pearson product-moment correlation coefficient was conducted to investigate the relationship between self-perceived athletic ability and attitude score. Despite the Pearson correlation being insignificant for all data combined, there was a significantly negative correlation between selfperceived athletic ability and attitude score, $r=-0.197, n=255, p=0.001$ for Chinese participants. This suggests that lower self-perceived athletic ability is correlated with a higher attitude score. Yet, for American participants, there was a positive correlation between the two variables, $\mathrm{r}=0.468, \mathrm{n}=$ $146, \mathrm{p}<0.001$, suggesting that higher self-perceived athletic ability corresponds to a higher attitude score.

No significant correlation was found between age and attitude score for both countries combined and separated. 


\section{Discussion}

The main purpose of this study is to explore the differences in high school students' attitudes toward physical education between two different systems of physical education: the Chinese system and the American system. Overall, high school students' attitudes towards physical education are positive for both systems. The results show that Chinese high school students have a better attitude. This may be explained by examining the Chinese education system. Physical activity is taken as a daily curriculum since the first grade in China, which contributes to the building of good exercising habits. Later on, in their path of education, physical education becomes a graded class that is weighted as part of the Zhongkao (Senior High School Entrance Examination) and Gaokao (National College Entrance Examination). Although physical education classes in China have factors shown by previous research to decrease attitude score such as pressure and lack of selection, Chinese high school students still feel the importance of practicing hard and performing well in PE. Due to the high-demanding physical education curriculum, Chinese high school students with a lower self-perceived athletic ability would need to treat physical education more seriously than their high-performing counterparts. However, many high schools in the United States do not give grades for physical education and student participation in physical activity is not reflected on the transcript. Therefore, American students may put less emphasis on physical education unless they are high-performing individuals such as athletics.

This study does not confirm the findings from previous research on the negative correlation between age and attitude towards physical education. Gender is found in this study to be a factor that affects attitude, confirming the findings of some previous research. This may be caused by social construct of gender roles, that boys are usually more encouraged to do sports. Chinese physical education classes often divide the boys and the girls as they are tested differently. For example, boys are tested on $1000 \mathrm{~m}$ sprints while girls are tested on $800 \mathrm{~m}$ sprints; curriculums for boys are more often focused on strength, girls on coordination. This may limit students' freedom of choosing within the limited options provided and reinforce traditional perceptions of male and female prowess, but it may also increase confidence by allowing boys and girls to do what many of them are better at. While enjoying more flexibility of choices, students from American high schools are often not pushed out of their comfort zones, which does not change the type and level of participation of physical activities for individuals, further reinforcing the divide in preferred activities between boys and girls.

The biggest difference between Chinese physical education and that of American schools is the impact of physical education on students' overall high school performance. A good starting point for a more rigorous high school physical education curriculum should aim at changing the students' views on the value of physical education. The most straightforward way to do so is by giving grades for physical education as a weighted part of GPA. While the Chinese physical education system is stressful for many students who are less good at sports, their attitude towards physical education is nevertheless better than their more athletic counterparts and the average American high school students. In order to respect the different physical abilities individual students, have, having each student graded based on their improvement may be helpful in boosting commitment to physical activities and promoting both physical and mental health. For example, a student's time for $800 \mathrm{~m}$ sprint is recorded at both the beginning and at the end of the course, and their grade is based on how much they improved (or failed to do so). Students should be required to do certain physical activities such as sprinting and jogging that trains the whole body, while also having the choice to select additional activities of their choice. A wider selection of physical activities may help increase student participation, therefore high schools should put effort into providing more options such as cardio boxing, weight-training, and first-aid.

Nonetheless, it is important to acknowledge that this study may be flawed as it was conducted in the form of an online survey. Sampling bias exists because of the voluntary nature of this survey, but is reduced by a relatively large sample size. In addition, the survey is a self-report survey, which means that the responses may not reflect the true beliefs of the participants. Due to the freedom of American high schools, the summary in this study may not provide a comprehensive view of physical education on American high schools due to the lack of studies and official descriptions. 


\section{Conclusion}

In this comparison study, it is found that students from Chinese high schools have a more positive attitude towards physical education than students from American schools. One of the possible ways to improve high school students' attitudes towards physical education worldwide is to incorporate the positive aspects of the two different systems of physical education. The Chinese schools' emphasis on performance helps establish the importance of physical education, while the big variety of selection offered by American high schools can encourage students to pursue their own interests and strengths. Therefore, by incorporating these aspects together into one system of education, the proposals are to a) establish physical education as a course that is graded based on individual growth which would be reflected on students' transcripts; b) offer physical education as a two-part curriculum, one part being mandatory physical activities, the other part being activities of students' individualized interests.

The importance of high school physical education cannot be understated. Physical education can benefit the adolescents both physically and mentally [7, 8], and can prepare them to enter into society as healthy and well-balanced adults. By improving the physical education systems worldwide, high school students would have a more positive attitude towards physical education which may lead to the establishment of beneficial life-long habits of physical activity.

\section{References}

[1]. Silverman, S., \& Subramaniam, P. (1999). Student attitude toward physical education and physical activity: a review of measurement issues and outcomes, Journal of Teaching in Physical Education, 19(1), 97-125. Retrieved Jul 29, 2019, from https:// journals. humankinetics. com/ view/ journals/jtpe/19/1/article-p97.xml.

[2]. Rikard, L \& Banville, Dominique. (2006). High school student attitudes about physical education. Sport, Education and Society, 11, 385-400.

[3]. Ajzen, I., \& Fishbein, M. (2005). The influence of attitudes on behavior. In D. Albarracín, B. T. Johnson, \& M. P. Zanna (Eds.), The handbook of attitudes (pp. 173-221). Mahwah, NJ, US: Lawrence Erlbaum Associates Publishers.

[4]. Zeng, H. Z., Hipscher, M., \& Leung, R. W. (2011). Attitudes of High School Students toward Physical Education and Their Sport Activity Preferences. Journal of Social Sciences, 7(4), 529537. https://doi.org/10.3844/jssp.2011.529.537.

[5]. Marttinen, R., N., R., Fredrick III, \& Silverman, S. (2018). Changes in student attitude toward physical education across a unit of instruction. Journal of Physical Education and Sport, 18(1).

[6]. Chung, M., \& Phillips, D. A. (2002). The relationship between attitude toward physical education and leisure-time exercise in high school students. Physical Educator, 59, 126-138.

[7]. Morgan, P. J., Saunders, K. L. \& Lubans, D. R. (2012), Improving physical self-perception in adolescent boys from disadvantaged schools: Psychological outcomes from the physical activity leaders randomized controlled trial. Pediatric Obesity, 7(3), 27-32.

[8]. Yilmaz, Aynur. (2018). Attitudes towards physical education course and extracurricular sport activities of parents -Ebeveynlerin beden eğitimi dersi ve ders dışı sportif etkinliklere yönelik tutumları. 12.

[9]. Ashutosh, A., Nrusingha, P., \& Anshuman, M. (2016). Students' sports activity preference and their attitudes toward physical education. International Journal of Modern Trends in Engineering and Research, 3(3).

[10]. Subramaniam, P.R., \& Silverman, S. (2007). Middle school students' attitudes toward physical education. Teaching and Teacher Education, 23, 602-611. 
[11]. Koca, C., \& Demirhan, G. (2004). An examination of high school students' attitudes toward physical education with regard to sex and sport participation. Perceptual and Motor Skills, 98, 754-758.

[12]. Zeng, H.Z., Wang, Y., \& Wang, X. (2016). A study of Chinese collegiate attitudes toward physical education.

[13]. Fairclough, S. (2006). Physical activity, perceived competence and enjoyment during high school physical education. European Journal of Physical Education, 8, 5-18.

[14]. Solmon, M.A., \& Carter, J.A. (1995). Kindergarten and first-grade students' perceptions of physical education in one teacher's classes. Elementary School Journal, 95, 355-365.

[15]. Bernstein, E., Phillips, S., \& Silverman, S. (2011). Attitudes and perceptions of middle school students toward competitive activities in physical education. Journal of Teaching in Physical Education, 30, 69-83.

[16]. Ajzen, I. (1991). The theory of planned behavior. Organizational Behavior and Human Decision Processes, 50(2), 179-211. https://doi.org/10.1016/0749-5978(91)90020-T.

[17]. Hopple, C., \& Graham, G. (1995). What children think, feel, and know about physical fitness testing. Journal of Teaching in Physical Education, 14, 408-417.

[18]. Ntoumanis N. (2001). A self-determination approach to the understanding of motivation in physical education. The British Journal of Educational Psychology, 71, 225-242. 